\title{
Metachronous liver metastases after long- term follow-up of endoscopic resection for rectal neuroendocrine neoplasms: a report of three cases
}

Yuma Hane ${ }^{1}$, Takahiro Tsuchikawa ${ }^{1 *}$, Kimitaka Tanaka ${ }^{1}$, Yoshitsugu Nakanishi ${ }^{1}$, Toshimichi Asano ${ }^{1}$, Takehiro Noji ${ }^{1}$, Yo Kurashima', Yuma Ebihara', Soichi Murakami ${ }^{1}$, Toru Nakamura', Keisuke Okamura', Satoshi Takeuchi²,

Toshiaki Shichinohe ${ }^{1}$ and Satoshi Hirano ${ }^{1}$

\begin{abstract}
Background: Rectal neuroendocrine neoplasms (NENs) are rare, but their incidence has increased in recent years. The metastasis rate is low in cases of a tumor diameter $<1 \mathrm{~cm}$ or depth of invasion lower than the submucosa; therefore, the European Neuroendocrine Tumor Society (ENETS) and the North American Neuroendocrine Tumor Society (NANETS) consensus guidelines recommend endoscopic resection. Since little has been reported on the long-term prognosis of endoscopic resection for rectal NEN, consensus is lacking regarding the follow-up period after endoscopic resection.

Case presentation: Here, we report three cases of metachronous liver metastasis after long-term follow-up of endoscopic mucosal resection (EMR) for rectal NEN. The pathological findings indicated a depth lower than the submucosa and complete radical resection in all cases and lymphovascular invasion in only one case. All three cases showed metachronous multiple liver metastases after 9-13 years of follow-up for EMR, despite achieving complete resection and without muscular invasion.
\end{abstract}

Conclusions: Metachronous liver metastases may occur after long interval following endoscopic resection; thus, long-term follow-up is necessary after endoscopic resection for rectal NEN.

Keywords: Neuroendocrine neoplasm, Endoscopic resection, Long-term follow-up, Recurrence

\section{Background}

Rectal neuroendocrine neoplasm (NEN) is a rare tumor derived from enterochromaffin cells with a reported incidence of 1.04 per 100,000 [1] that has recently been increasing. With the spread of chance to take the screening endoscopes, $93.3-100 \%$ are diagnosed at $1 \mathrm{~cm}$ or less [2]. NEN is described as a low-grade malignant tumor according to World Health Organization classification; however, the prognosis in cases of lymph node and distant metastasis is as poor as that of adenocarcinoma [3]. The metastasis

\footnotetext{
* Correspondence: tsuchi-t@med.hokudai.ac.jp

'Department of Gastroenterological Surgery II, Division of Surgery, Faculty of Medicine, Hokkaido University, West-7, North-15, Kita-ku, Sapporo 060-8638, Japan

Full list of author information is available at the end of the article
}

rate at diagnosis is low in 3-9.7\% of tumors measuring < $10 \mathrm{~mm}[4,5]$; therefore, the European Neuroendocrine Tumor Society (ENETS), North American Neuroendocrine Tumor Society (NANETS), and Japanese Neuroendocrine Tumor Society (JNETS) guidelines recommend endoscopic resection in cases of tumors $<10 \mathrm{~mm}$ without muscular invasion [6,7]. Moreover, the metastasis rate at diagnosis is high in $56.7-73 \%$ of tumors measuring $>20$ $\mathrm{mm}[4,5]$, and surgical resection with prophylactic lymph node dissection is recommended as with colorectal carcinoma. On the other hand, endoscopic resection for intermediate tumors measuring $10-20 \mathrm{~mm}$ is considered as expanded indication despite little evidence $[4,8]$.

Collectively, in terms of the treatment options for rectal $\mathrm{NEN}<20 \mathrm{~mm}$, there are several options for endoscopic 
resection, including additional surgical resection with prophylactic lymph node dissection and appropriate follow-up periods, depending on the global guidelines due to little information about and evidence of long-term prognosis after endoscopic resection for rectal NEN. Here, we report three cases of metachronous liver metastasis after long-term follow-up of endoscopic mucosal resection (EMR) and discuss the current problems underlying the treatment options for small rectal NEN with a review of the literature.

\section{Case presentation \\ Case 1}

A 55-year-old woman underwent EMR for rectal NEN (Fig. 1). The pathological findings were as follows: welldifferentiated NEN, tumor size $13 \mathrm{~mm}$, no muscular invasion (submucosa), negative resection margins, no lymphovascular invasion, and $\mathrm{Ki}-67<1 \%$. She underwent colonoscopy at 1, 2, 3, 6, and 9 years after EMR for rectal NEN, but no recurrence was revealed. At 10 years after EMR, she visited our hospital complaining of bloating, weight loss, and leg edema. Abdominal computed tomography $(\mathrm{CT})$ revealed multiple liver masses in the bilateral lobe (Fig. 2a) diagnosed as multiple liver metastases by biopsy concordant with the initial tumor. Since immunohistochemistry staining of the liver metastasis showed somatostatin-2 receptor (SSTR-2) positivity, monthly intramuscular octreotide $30 \mathrm{mg}$ was administered. The symptoms got worse, and daily oral everolimus $10 \mathrm{mg}$ was added 4 months after the initial treatment. However, she developed pneumonia 3 weeks after the start of everolimus. Everolimus was changed to weekly streptozocin $1000 \mathrm{mg}$. Stable disease (SD) was achieved and maintained

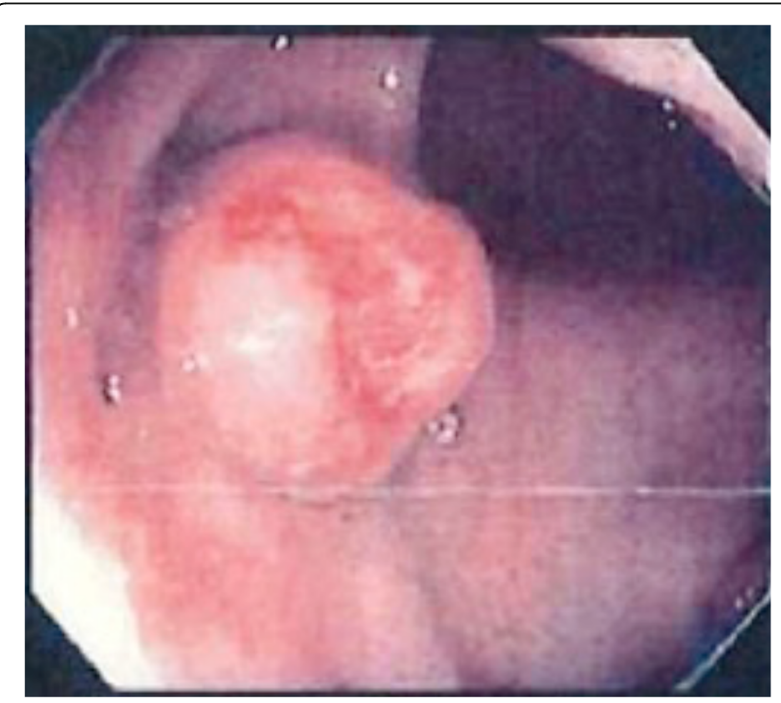

Fig. 1 Endoscopy image of the primary tumor in case 1. Submucosal tumor with ulcer in the rectum for 6 months after the initial treatment; however, it was discontinued due to liver failure. She died of liver metastasis 1 year after the initial treatment.

\section{Case 2}

A 59-year-old woman underwent EMR for rectal NEN. The pathological findings were as follows: welldifferentiated NEN, tumor size $10 \mathrm{~mm}$, no muscular invasion (submucosa), negative resection margin, no lymphovascular invasion, and Ki-67 $=5 \%$. A comprehensive medical checkup performed 9 years after EMR revealed two liver masses derived from S4 $(15 \mathrm{~mm})$ and S6/7 (15 $\mathrm{mm}$ ) as well as a pelvic mass (18 mm) on CT (Fig. 2b, c). No tumors had infiltrated the adjacent tissues. Fine needle aspiration (FNA) and liver biopsy of the S4 liver mass revealed local recurrence and multiple liver metastases. She previously underwent laparoscopic low anterior resection (LAR) of the local recurrence in a prior hospital and radiofrequency ablation (RFA) for liver metastases. Pathological findings of pelvic mass resected by LAR revealed SSTR-2 positivity; therefore, she was started on monthly intramuscular octreotide $30 \mathrm{mg}$ and was followed up for 3 months. However, CT revealed new liver metastasis in S3 at 1 year after the initial treatment for which she underwent RFA. Daily oral everolimus $10 \mathrm{mg}$ was added. Since the liver metastasis was again enlarged 2 years after the initial treatment, weekly streptozocin $1000 \mathrm{mg}$ administration was started. However, CT revealed enlargement of multiple liver metastases at 3 months after the first streptozocin administration; therefore, transhepatic arterial chemoembolization was performed. She has maintained stable disease (SD) for 3 years from the diagnosis of recurrence.

\section{Case 3}

A 54-year-old man underwent EMR for rectal NEN. The pathological findings were as follows: well-differentiated $\mathrm{NEN}$, tumor size $12 \mathrm{~mm}$, no muscular invasion (submucosa), negative resection margins, positive vascular invasion, chromogranin positivity, synaptophysin positivity, and Ki-67 $=1.7 \%$. He visited a nearby hospital complaining of right epigastric pain 13 years after the EMR. It was diagnosed as intraductal papillary mucinous neoplasm and pancreatitis. CT on admission showed multiple liver masses (Fig. 2d). A liver biopsy revealed multiple liver metastases derived from S6 $(47 \mathrm{~mm})$. $\mathrm{He}$ received daily oral everolimus $10 \mathrm{mg}$ and has maintained SD for 3 years and 3 months since the diagnosis of liver metastases.

\section{Discussion}

In this report, we showed three cases of metachronous liver metastasis after long-term follow-up of EMR for rectal NEN. For each case, EMR was performed according to the expanded indication of endoscopic resection 

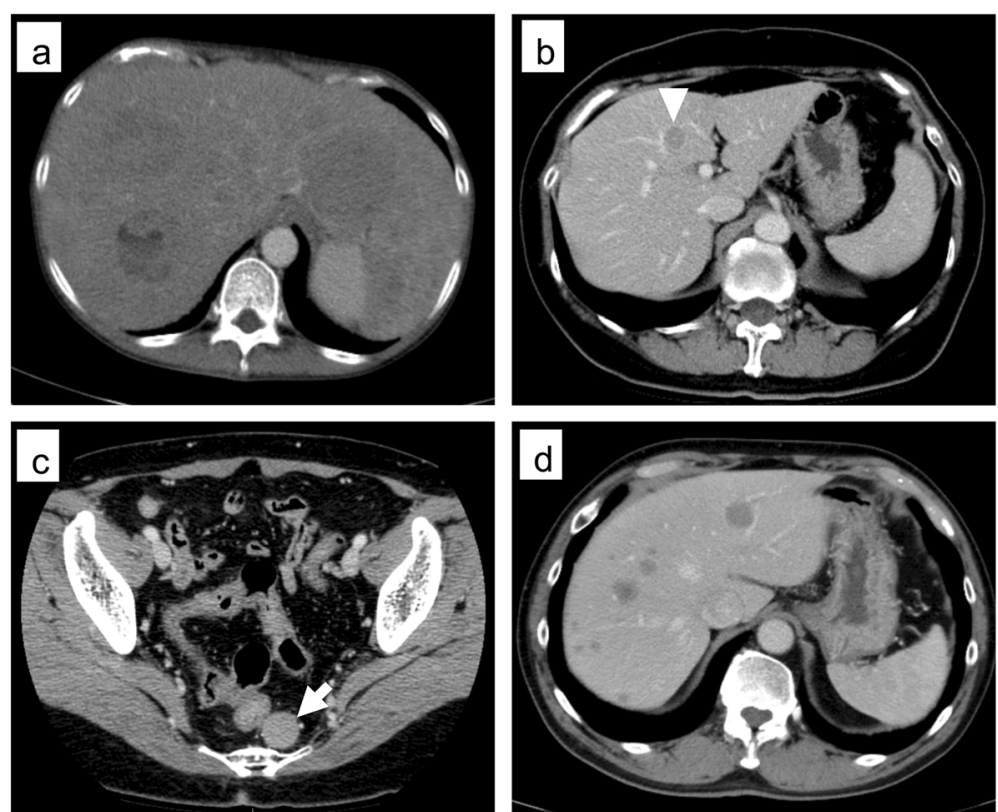

Fig. 2 Selected images from abdominal computer tomography. a Case 1: multiple low-density lobular lesions in the bilateral lobe. b Case 2: lowdensity lesion in $\mathbf{S 4}$ (arrowhead). c Case 2: left dorsal recurrent mass of the rectum (arrow). $\mathbf{d}$ Case 3: multiple low-density lesions in the bilateral lobe

in the ENETS and NANETS guidelines. Complete curative resection was achieved in all three cases; therefore, additional resection did not perform. To our knowledge, this is the first report of metachronous liver metastases after the long-term follow-up of EMR for rectal NEN despite achieving complete resection without histologically proven in-depth muscular invasion.

First, regarding indications of endoscopic tumor resection for rectal NEN, NANETS and JNETS guidelines recommend endoscopic resection in cases of a tumor $<10$ $\mathrm{mm}$ without muscular invasion [7], while ENETS guidelines recommend it in cases of a tumor $<10 \mathrm{~mm}, \mathrm{G1}$ or G2, and no muscular invasion [6] because the metastasis rate at diagnosis is reportedly low in $3-9.7 \%$ of tumors measuring $<10 \mathrm{~mm}[4,5]$. On the other hand, endoscopic resection of intermediate $10-20 \mathrm{~mm}$ tumors is considered to be of moderate risk despite little evidence $[4,8]$. Tumor size $>10 \mathrm{~mm}$, muscular invasion, lymphovascular invasion, mitotic rate $>2 / 10$ high-powered field, and Ki-67 $>2 \%$ are reported as the risk factors reflecting liver and lymph node metastasis in the literature [9]. Moreover, Konishi et al. [3] reported that a tumor size $>10 \mathrm{~mm}$ is the risk factor of lymph node metastasis and that the prognosis in case of lymph node and distant metastasis is as poor as that of adenocarcinoma; therefore, they recommend surgical resection with lymph node dissection in cases of a tumor size $>10 \mathrm{~mm}$. On the other hand, some reported on the applicability of endoscopic resection in case of intermediate $10-20 \mathrm{~mm}$ tumor. In a systematic review, Zhong et al. [10] reported that endoscopic submucosal dissection could be an appropriate treatment choice for tumors smaller than $16 \mathrm{~mm}$ in diameter due to the low metastasis rate. Shigeta et al. [11] reported local resection for the high-risk group with a tumor size $>10 \mathrm{~mm}$, that positive lymphovascular invasion developed recurrence in only $1(4 \%)$ of 24 patients (median observation period, 55 months), and that there was no difference in the recurrence rates of high-risk patients who underwent local resection and those who underwent radical resection. They concluded that local resection could be an appropriate treatment choice for tumors measuring $10-20 \mathrm{~mm}$. Thus, appropriate criteria to indicate endoscopic resection are quite controversial. In our three cases, the pathological findings revealed that all tumors were limited to the submucosa and tumor size was 10-13 mm (Table 1). Therefore, EMR was considered retrospectively acceptable according to the expanded indication of endoscopic resection in the recent NANETS and ENETS guidelines.

No consensus was reached on the indications for additional resection after endoscopic resection. The JNETS guideline 2019 highly recommends surgical resection with lymph node dissection as additional resection in the cases that pathological findings indicate lymphovascular invasion, muscular invasion, positive resection margin, and G2 or more, according to the risk factors of lymph node metastasis. ENETS guidelines suggest 6 months of follow-up in cases of G1 with incomplete resection and recommend complete local resection for G2 [6]. On the other hand, Sekiguchi et al. [8] reported no recurrence in cases of positive or negative lymphovascular invasion detected by 
Table 1 Summary of pathological findings of the primary tumor and recurrence

\begin{tabular}{|c|c|c|c|c|c|c|c|c|}
\hline $\begin{array}{l}\text { Case } \\
\text { no. }\end{array}$ & Age/sex & $\begin{array}{l}\text { Tumor size } \\
(\mathrm{mm})\end{array}$ & Depth & Margin & $\begin{array}{l}\text { Lymphovascular } \\
\text { invasion }\end{array}$ & Ki-67 & $\begin{array}{l}\text { Recurrence site (Ki- } \\
67)\end{array}$ & $\begin{array}{l}\text { Relapse-free survival } \\
\text { (years) }\end{array}$ \\
\hline No. 1 & $\begin{array}{l}55 / \\
\text { female }\end{array}$ & 13 & Submucosa & Negative & Negative & $\begin{array}{l}<1 \% \\
(\mathrm{G} 1)\end{array}$ & Liver (8.4\%) & 10 \\
\hline No. 2 & $\begin{array}{l}59 / \\
\text { female }\end{array}$ & 10 & Submucosa & Negative & Negative & $5 \%(G 2)$ & $\begin{array}{l}\text { Liver and rectum } \\
(5 \%)\end{array}$ & 9 \\
\hline No. 3 & 54/male & 12 & Submucosa & Negative & Positive & $1.7 \%(\mathrm{G} 1)$ & Liver (10\%) & 13 \\
\hline
\end{tabular}

CD31/synaptophysin double staining and elastic staining; therefore, they insisted that lymphovascular invasion is not a risk factor of recurrence after endoscopic resection. However, their study did not include a long-term followup period (median observation time, 67.5 months). In our report, cases 2 and 3 had risk factors for lymph node and liver metastasis described above in terms of Ki-67 (>2\%, case 2 ) and positive vascular invasion (case 3 ). There was the potential risk that positive vascular margins caused the liver metastasis in case 3. In our pathological findings, cases 1 and 2 had no lymphovascular invasion. Sekiguchi et al. [8] also revealed vascular invasion was detected by CD31/synaptophysin double staining and elastic staining in $38.9 \%$ compared with HE staining alone in only $1 \%$. Thus, it was possible that the prevalence of vascular invasion was underestimated in cases 1 and 2 .

Little has been reported about recurrence after longterm follow-up of endoscopic resection for rectal NEN. The five existing reports with long-term follow-up after endoscopic resection are summarized in Table 2. Sekiguchi et al. [8] and Onozato et al. [12] reported no recurrence after endoscopic resection; however, both reports had follow-up periods that were shorter than 7 years. On the other hand, Kwaan et al. [13], Kobayashi et al. [14], and Shigeta et al. [11] reported local recurrence or liver metastasis; however, these reports were cases with positive margins, muscular invasion, or relatively large tumor size. Thus, it is possible that the treatment plan consisting of endoscopic resection and additional resection was inappropriate. In our report, there were no cases with positive margins, and the tumor size was relatively small (10-13 mm); nevertheless, liver metastases were observed during a long-term follow-up period of 9-13 years after endoscopic resection.

Finally, no consensus has been reached on follow-up period or modality after endoscopic resection. Accordingly, follow-up period and modality differ among guidelines; moreover, no consensus has been reached among facilities in the same country. Lifelong follow-up is considered necessary in ENETS guidelines, as rectal NEN oncologically grows slowly; recurrence was detected at 13 years in our report (case 3 ). Our report had the limitation that the percentage of metachronous metastases in all patients who underwent endoscopic resection was not investigated. Following all patients who undergo endoscopic resection is highly expensive; therefore, follow-up is required to carefully select high-risk patients. More evidence is required to determine the follow-up strategy after endoscopic resection for rectal NEN.

\section{Conclusions}

Metachronous metastases may occur from endoscopic resection to a long period thereafter; thus, long-term followup is necessary after endoscopic resection for rectal NEN. No consensus has been reached on follow-up period or modality after endoscopic resection for rectal NEN. This report may assist with the determination of follow-up strategy after endoscopic resection for rectal NEN.

Table 2 Existing reports describing follow-up after endoscopic resection

\begin{tabular}{|c|c|c|c|c|c|c|}
\hline & Number & $\begin{array}{l}\text { Median observation period } \\
\text { (month) }\end{array}$ & $\begin{array}{l}\text { Recurrence } \\
\text { (\%) }\end{array}$ & $\begin{array}{l}\text { Recurrence } \\
\text { site }\end{array}$ & $\begin{array}{l}\text { Relapse-free survival } \\
\text { (years) }\end{array}$ & Features of recurrent cases \\
\hline $\begin{array}{l}\text { Sekiguchi et al. } \\
\text { [8] }\end{array}$ & 86 & 67 & 0 & - & - & - \\
\hline $\begin{array}{l}\text { Onozato et al. } \\
{[12]}\end{array}$ & 38 & 77 & 0 & - & - & - \\
\hline $\begin{array}{l}\text { Shigeta et al. } \\
\text { [11] }\end{array}$ & 74 & 31 & $1(1.4)$ & Local & 6 & Tumor size 20 mm \\
\hline Kwaan et al. [13] & 46 & 24 & $1(2.1)$ & Liver & 5 & $\begin{array}{l}\text { Positive resection margin, muscular } \\
\text { invasion }\end{array}$ \\
\hline $\begin{array}{l}\text { Kobayashi et al. } \\
{[14]}\end{array}$ & 38 & 43 & $1(2.6)$ & Local & 16 & Positive resection margin \\
\hline
\end{tabular}




\section{Abbreviations}

$\mathrm{CT}$ : Computed tomography; EMR: Endoscopic mucosal resection; ENETS: European Neuroendocrine Tumor Society; FNA: Fine needle aspiration; JNETS: Japanese Neuroendocrine Tumor Society; LAR: Low anterior resection; NANETS: North American Neuroendocrine Tumor Society; NEN: Neuroendocrine neoplasm; RFA: Radiofrequency ablation; SD: Stable disease; SSTR-2: Somatostatin-2 receptor

\section{Acknowledgements}

We would like to thank Editage (www.editage.jp) for English language editing.

\section{Authors' contributions}

$\mathrm{YH}$ and $T \mathrm{~d}$ drafted the manuscript. KT, YN, TA, TN, YK, YE, SM, TN, KO, ST, TS, and $\mathrm{SH}$ critically revised the manuscript. All authors read and approved the final manuscript.

\section{Funding}

Not applicable

\section{Availability of data and materials}

Not applicable

\section{Ethics approval and consent to participate}

Not applicable

\section{Consent for publication}

Written informed consent was obtained from the patients for publication of this case report and the accompanying images. A copy of the written consent is available for review by the Editor of this journal.

\section{Competing interests}

The authors declare that they have no competing interests.

\section{Author details}

'Department of Gastroenterological Surgery II, Division of Surgery, Faculty of Medicine, Hokkaido University, West-7, North-15, Kita-ku, Sapporo 060-8638, Japan. ${ }^{2}$ Department of Medical Oncology, Graduate School of Medicine, Hokkaido University, Sapporo, Japan.

Received: 31 October 2019 Accepted: 10 January 2020

Published online: 15 January 2020

\section{References}

1. Dasari A, Shen C, Halperin D, Zhao B, Zhou S, Xu Y, et al. Trends in the incidence, prevalence, and survival outcomes in patients with neuroendocrine tumors in the United States. JAMA Oncol. 2017:3:1335-42.

2. Scherubl H. Rectal carcinoids are on the rise: early detection by screening endoscopy. Endoscopy. 2009:41:162-5.

3. Konishi T, Watanabe T, Kishimoto J, Kotake K, Muto T, Nagawa H. Prognosis and risk factors of metastasis in colorectal carcinoids: results of a nationwide registry over 15 years. Gut. 2007:56:863-8.

4. Gleeson FC, Levy MJ, Dozois EJ, Larson DW, Wong Kee Song LM, Boardman LA. Endoscopically identified well-differentiated rectal carcinoid tumors: impact of tumor size on the natural history and outcomes. Gastrointest Endosc. 2014;80:144-51.

5. Soga J. Early-stage carcinoids of the gastrointestinal tract: an analysis of 1914 reported cases. Cancer. 2005:103:1587-95.

6. Ramage JK, De Herder WW, Delle Fave G, Ferolla P, Ferone D, Ito T, et al ENETS consensus guidelines update for colorectal neuroendocrine neoplasms. Neuroendocrinology. 2016;103:139-43.

7. Kunz PL, Reidy-Lagunes D, Anthony LB, Bertino EM, Brendtro K, Chan JA, et al. Consensus guidelines for the management and treatment of neuroendocrine tumors. Pancreas. 2013;42:557-77.

8. Sekiguchi M, Sekine S, Sakamoto T, Otake Y, Nakajima T, Matsuda T, et al. Excellent prognosis following endoscopic resection of patients with rectal neuroendocrine tumors despite the frequent presence of lymphovascular invasion. J Gastroenterol. 2015;50:1184-9.

9. Iwashita A, Haraoka S, Ikeda K, Tsuda S, Ueki T, Iwasaki H, et al. Clinicopathological study on carcinoid tumor of the rectum: mainly on comparison of cases with metastasis and those without metastasis (in Japanese with English abstract). Stomach Intestine. 2005:40:151-62.

10. Zhong DD, Shao LM, Cai JT. Endoscopic mucosal resection vs endoscopic submucosal dissection for rectal carcinoid tumours: a systematic review and meta-analysis. Color Dis. 2013;15:283-91.

11. Shigeta K, Okabayashi K, Hasegawa H, Ishii Y, Ochiai H, Tsuruta M, et al. Long-term outcome of patients with locally resected high- and low-risk rectal carcinoid tumors. J Gastrointest Surg. 2014;18:768-73.

12. Onozato $Y$, Kakizaki S, lizuka H, Sohara N, Mori M, Itoh H. Endoscopic treatment of rectal carcinoid tumors. Dis Colon Rectum. 2010;53:169-76.

13. Kwaan MR, Goldberg JE, Bleday R. Rectal carcinoid tumors: review of results after endoscopic and surgical therapy. Arch Surg. 2008;143:471-5.

14. Kobayashi K, Katsumata T, Yoshizawa S, Sada M, Igarashi M, Saigenji K, et al. Indications of endoscopic polypectomy for rectal carcinoid tumors and clinical usefulness of endoscopic ultrasonography. Dis Colon Rectum. 2005; 48:285-91.

\section{Publisher's Note}

Springer Nature remains neutral with regard to jurisdictional claims in published maps and institutional affiliations.

\section{Submit your manuscript to a SpringerOpen ${ }^{\circ}$ journal and benefit from:}

- Convenient online submission

- Rigorous peer review

- Open access: articles freely available online

- High visibility within the field

- Retaining the copyright to your article

Submit your next manuscript at $\boldsymbol{\nabla}$ springeropen.com 